\title{
DURATION OF LOAD EFFECTS ON DEVELOPMENT OF DEFORMATIONS IN BOLTED MOMENT CONNECTION
}

\author{
*Janis Fabriciuss, Lilita Ozola \\ Latvia University of Life Sciences and Technologies, Latvia \\ *Corresponding author’s email: janis.fabriciuss@inbox.lv
}

\begin{abstract}
Experience saved in the construction industry shows that the timber portal frames with semi-rigid connections at knee joint exhibit permanently increase displacements at the knee and apex point. Normally, timber portal frame with semi-rigid knee joint connection is made with mechanical fasteners located in double circles and cannot be designed without relevant rotation at connection during structures' exploitation time. The only way to increase connection rigidity is to rise distance from fasteners location at connection, but at the same time, the tension and shear stress become significant at the external section of members. The previous experience is obtained by a model testing showing that deformations at semi-rigid connections are non-linear. These were tests under short-term load and did not disclose creep effects, which can be significant.

This study is aimed at the examination of increasing deformations with time under constant static load (creep effects) in semi-rigid dowelled connection.

Experimental test models were made and set under long-term load in controlled environmental conditions (heated laboratory room). Results show a significant creep influence to decrease connection stiffness.

Corresponding numerical test of orthotropic 3d model by Dlubal RFEM software tools was performed analyzing the value of expected deformations. Results of the numerical test showed that friction between timber elements and extra nuts on bolts can increase connection stiffness.

Research results in this stage show that the creep can affect connection stiffness more than expected. Also, experimental test results showed lower deformation values comparing with the ones obtained by the numerical test.

Key words: semi-rigid timber connection, creep, rotational movement, modeling of connection, portal frames.
\end{abstract}

\section{Introduction}

Portal frame is one of the most used structural forms in the modern construction industry because of the extra free space under the bearing structure, as well as much shorter time is needed for assembling in the construction site. Steel portal frames are wellknown structures, but there is an option to use more renewable resources and choose the same solution using timber material. Definition of appropriate design presumptions for the knee joint both made as glued finger joint and by mechanical fasteners, one is the core problem in the design of timber portal frames. The portal frame structure remains stable during service if the column and rafter sections are stiff enough to transfer stresses induced by external loads, and knee joints are so rigid that small rotational movements probably developed do not cause global deformations of a portal frame out of limits. Knee joint connection made as glued finger joints ensure high rigidity and fully stable three-hinged portal frame structure. But glued finger joint connection normally is produced in the factory far from a building site. Therefore, the main problem is the transportation of prefabricated big scale units from the factory to the building site. Due to transport limitations, it is also a limited area of use of timber portal frames with glued finger joints in the knee. Integration of the semirigid bolted connection in the knee joint resolves the transportation problem, as column and rafter members can be assembled together by mechanical fasteners at the building site.
Semi-rigid connection is normally made by mechanical fasteners (bolts) located in double circles. This connection characterizes specific behavior features under the load. Non-linear deformation is in progress. These effects were discussed previously in other investigations (Schweigler, Bader, \& Hochreiner, 2018). The connection exhibits a relevant rotational movement. Therefore, rigidity of connection is decreased. The rigidity of semi-rigid connection can be increased by the relocation of mechanical fasteners, i.e., increasing the distance between fasteners in an external circle, as well as from the center of connection. Also, using a higher strength class of glulam can lead to an increase of connection stiffness, but this solution is ineffective in an economic sense. Another problem in semi-rigid bolted connections is shear and cross-grain tension stresses induced in wood sections between mechanical fasteners and timber, especially in zones where the distance between fastener and connection center is higher. Ormarsson showed the effect in his investigation (Ormarsson, Dahlblom, \& Nygaard, 2010).

One of the first researchers who investigated the behaviour of semi-rigid timber element connections with a purpose to define the design model for bearing capacity calculations, were Racher (Bouchair, Racher, \& Bocquet, 2007), Porteous, Kermani (Porteous \& Kermani, 2013). Leichti summarized that resisting moment at semi-rigid knee joint can be expressed as the function of stiffness properties (Leichti et al., 2000). Assumptions for the calculation of connection 
bearing capacity was described in the previous article (Ozola \& Fabriciuss, 2019). Researchers also defined that the geometrical center of mechanical fasteners in connection can also be defined as a rotational center of connection or simply - a center of joint (Bouchair, Racher, \& Bocquet, 2007). Detail investigation of semi-rigid moment connections has been performed by Fokken (Fokkens, 2017).

Stiffness of the semi-rigid connection can be characterized by a rotational stiffness modulus $\mathrm{K} \varphi$ expressed as the moment value inducing the rotation between connected elements on an angle of one radian $\left(\mathrm{kNm} \cdot \mathrm{rad}^{-1}\right)$. For portal frame design considerations, it is aimful to express the rotational stiffness modulus in terms of design moment value $\mathrm{Md}: \mathrm{K}_{\varphi}=\mathrm{k}_{\mathrm{sr}} \cdot \mathrm{M}_{\mathrm{d}} \cdot \mathrm{rad}^{-1}$, where $\mathrm{k}_{\mathrm{sr}}$ is rigidity factor to be determined. In Eurocode (Europe structural engineers guideline) slip modulus $\mathrm{k}_{\mathrm{sr}}$ is defined only for linear displacement connection where force direction transferred by fasteners is usually in the same direction as timber grain (European committee for standardization, 2008). At a knee connection of timber portal frame force from a beam element to mechanical fastener and column element is transferred in multiple directions for individual bolts regarding wood fibers, so Eurocode methodology could not be applied safely in this case.

All previously obtained experimental test results were collected from short-term loading without making long-term loading tests to investigate creep effects on semi-rigid connection deformations in time. Eurocode did not give exact information about creep effects on a semi-rigid connection. As an example, the researcher Hanhijärvi (Hanhijärvi, 2000) made a significant impact on making background analysis of the creep phenomena.

This investigation is aimed at revealing the difference between theoretical numerical test results with experimental test results and finding more significant factors that can affect the rotational stiffness of semi-rigid connection during service life.

The main tasks of this study: 1) design and determination of bearing capacity of L-type model according to Eurocode 5 (European committee for standardization, 2008), 2) performing of experimental tests for L-type models in long term loading and collection of data daily, 3) numeralical test of L-type model using Dlubal RFEM software tools, 4) comparison of test results and coclusions.

\section{Materials and Methods}

The methods appropriate for attaining the aims of this investigation were chosen. The theoretical model for the numerical test was constituted correspondingly choosing Dlubal RFEM software tools and options for introducing of spring hinges in order to resolve the non-linear model. The experimental model was made in a laboratory and tested under a long-term static load. Test specimens are of L-type models simulating

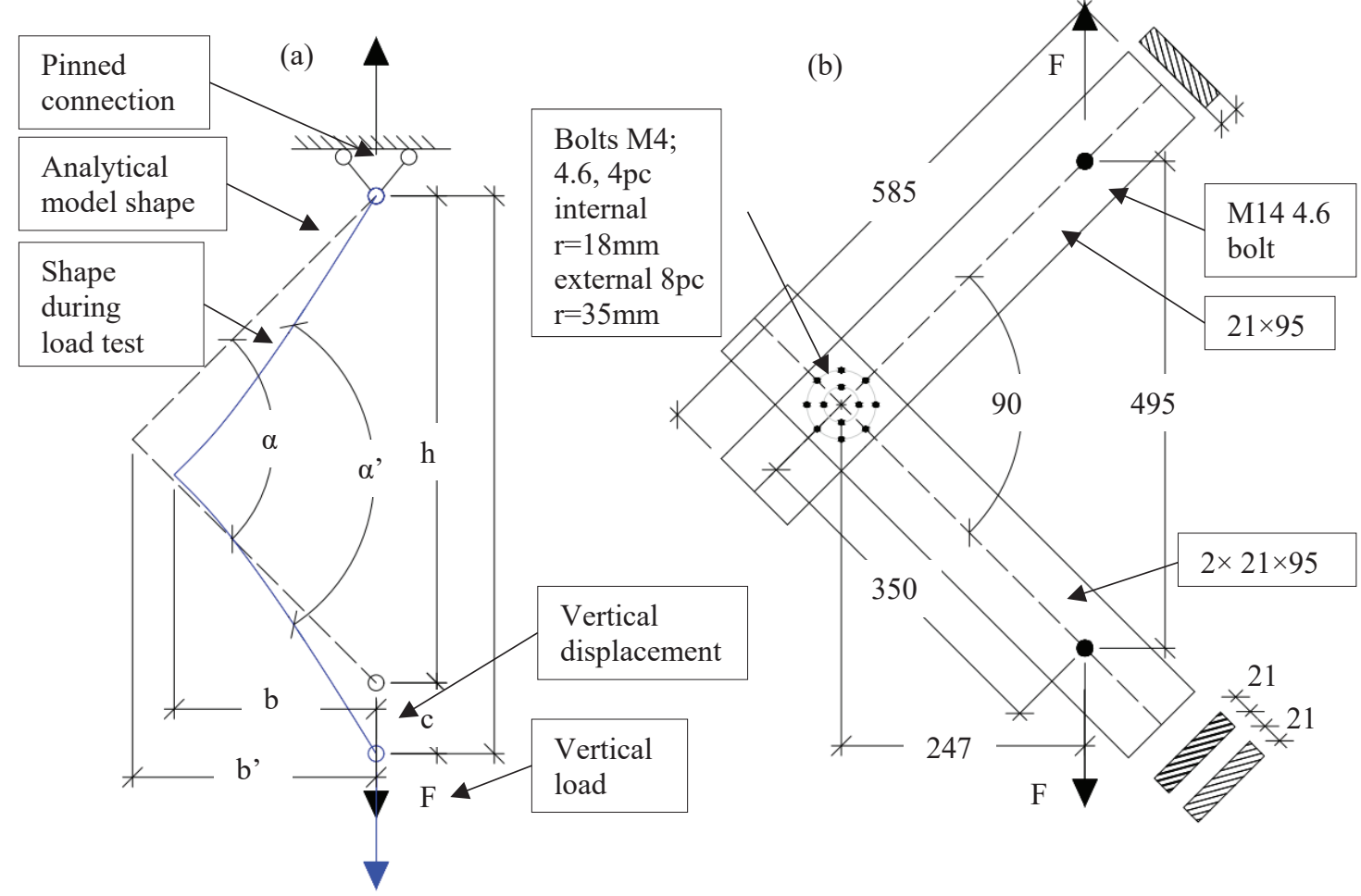

Figure 1. L type model analytical shape and dimensions ( $\mathrm{mm})$; a - analytical shape; $\mathrm{b}$ - shape during load tests in a laboratory. 


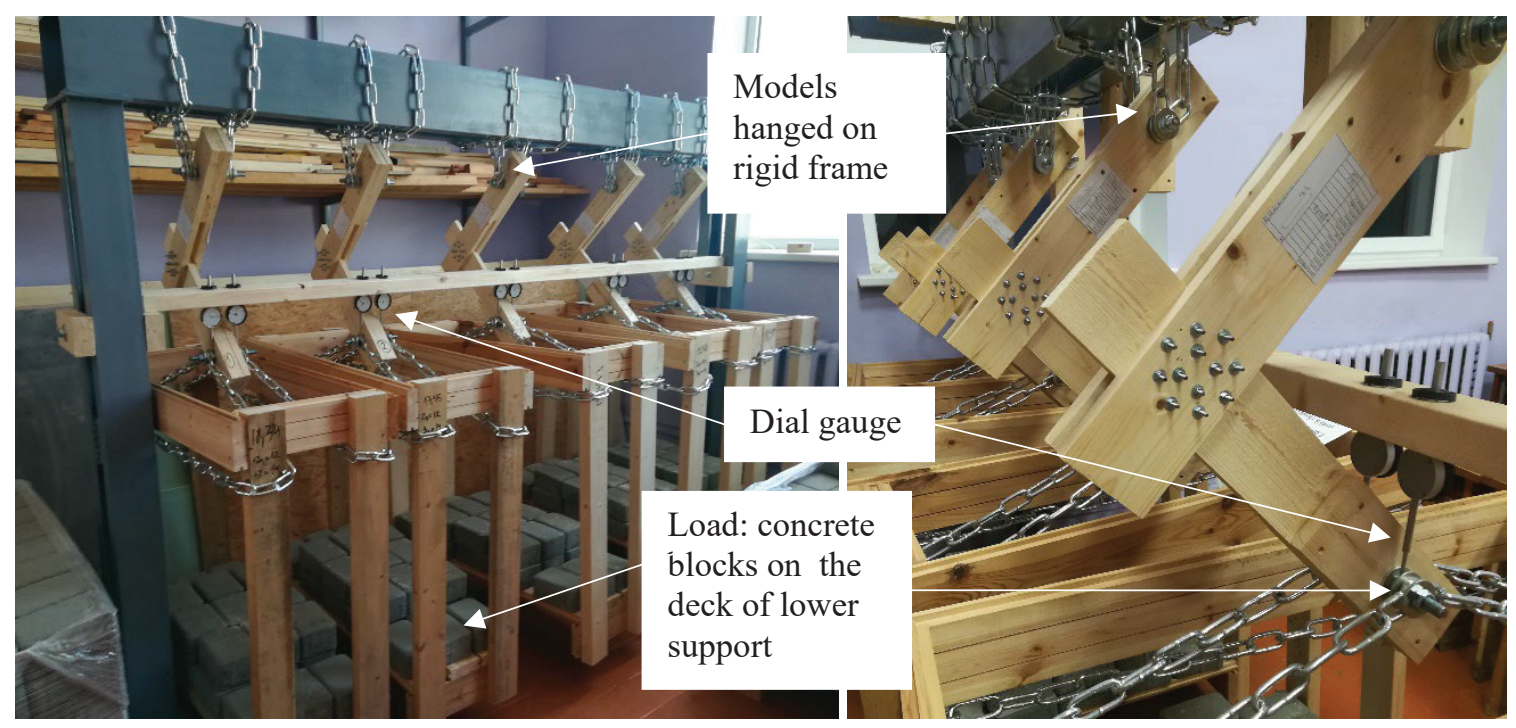

Figure 2. Experimental setup for long-term tests of L-type models.

the shape of the beam and column connection in the timber portal frame (Figure 1a). Simmilar model shape has been taken in Awaludin research (Awaludin etc. 2010).

The experimental models are made of softwood lumber (spruce Picea Abies), cross-section $21 \times 95 \mathrm{~mm}$ (Figure 1b). The moisture content of wood is in the range of $5 \%$ to $11 \%$, it is measured using the Wood Moisture Meter MD-2G. The average mass density of the wood varies from $330 \mathrm{~kg} \cdot \mathrm{m}^{-3}$ to $400 \mathrm{~kg} \cdot \mathrm{m}^{-3}$ in dry condition. Semi-rigid connection is formed by twelve bolts M4 (metric threaded rods, $\mathrm{d}=4 \mathrm{~mm}$ grade 4.8, DIN 976), which are placed around two circles. Four bolts are located around the internal circle and eight bolts are placed around the external one. All bolts from both sides were fixed by washers and nuts. Hole diameters for rods are the same as the nominal for rods; therefore, any free movements in connection were prevented. The lumber was free of cracks and straight of grain. Some small knots were found in lumber apart from the fastener location area. Support joints are assembled using bolts M14 (metric threaded, $\mathrm{d}=14 \mathrm{~mm}$, grade 4.8 ) in the center of lumber elements. Higher support was hanged to the rigid frame and vertical downward load is attached to lower support. Before the load was attached, models were stiffened with gasket $-21 \times 95 \mathrm{~mm}$ timber elements at the support zone. In total five experiment models were made.

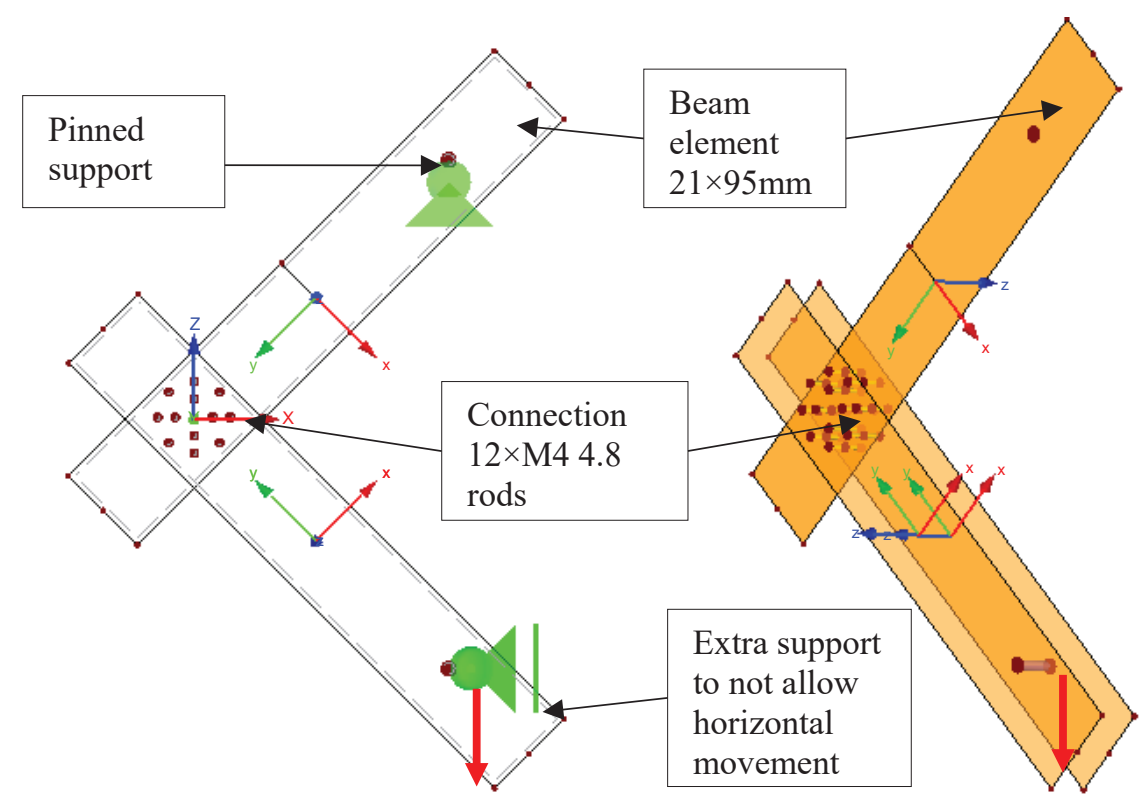

Figure 3. Analytical L-type model in Dlubal (RFEM). 
Experimental tests were performed in the laboratory of Structural Engineering, Faculty of Environment and Civil Engineering, Latvia University of Life Science and Technologies, from April 2019 till now. Research was made under controlled microclimate conditions (heated room).

The load was attached manually by concrete weights (Figure 2). The experimental models were loaded stepwise: during the first 60 minutes till load reaches approximately $50 \%$ from overall semi-rigid connection load-bearing capacity $-1160 \mathrm{~N}$ at lower support. Average models bearing capacity was 524 $\mathrm{N} \cdot \mathrm{m}$ at connection. During stepwise loading, vertical displacement was measured at lower support by dial gauges. Dial gauges were mounted on an independent stiff beam. In the second step, the constant vertical load was kept for nine months. Vertical displacements were measured daily during all tested time simultaneously performing monitoring of air temperature and relative humidity.

The analytical model was constituted to simulate the experimental model as close as possible by tools of Dlubal RFEM. Beam and column elements were modeled as surface elements and rods were modeled as members (Figure 3). The material of surface elements was classified as softwood lumber of strength class C30 assessed by visual grading rules. Rod member connections at crossing points with lumber surface elements were defined as rigid with spring constant $\mathrm{c}_{\mathrm{ux}}$. Spring constant was defined differently in every rod taking into account the angle between grain direction and shear force direction transferred by a fastener. The value of spring constant varied from $3430 \mathrm{kN} \cdot \mathrm{m}^{-1}$ up to $4830 \mathrm{kN} \cdot \mathrm{m}^{-1}$ depending on force angle to the grain direction.

\section{Results and Discussion}

The measurements of the vertical movement were collected for every L-type model during longterm loading. Models demonstrated a huge vertical movement on the first day, which was approximately $60 \%$ from overall deformation. Later, an average increase of displacements was $1 \mathrm{~mm}$ per day for every of sixty test days. Vertical displacements measured serve as the main characteristic for rotational deformation of connection. Increase of deformation by time can be characterized by linear relationship (1);

$$
\mathrm{k}_{\mathrm{t}}=\Delta_{\mathrm{t}} \cdot \mathrm{T}^{-1}
$$

where $\Delta_{\mathrm{t}}$ is the deformation at time.

Average deformations in time for L-type models were $\mathrm{kt}=0.041 \mathrm{~mm} \cdot \mathrm{day}^{-1}$. All results from experimental investigations are collected in Figure 4. Average vertical displacement for the model member after one day was $6.9 \mathrm{~mm}$, and after 280 days $-11.6 \mathrm{~mm}$.

The development of deformations in time may be characterized by the relative creep or creep coefficient, which is a general nondimensional indicator of creep (Hunt, 1999). The relative creep is expressed in terms of the initial elastic deflection $\left(u_{\mathrm{o}}\right)$ :

$$
c_{r}(t, T, M C)=\frac{u_{t}-u_{O}}{u_{o}} \cdot 100 \%
$$

where $u_{t}$ is the displacement at a time (t) in step with air temperature ( $\mathrm{t}$ ) at a laboratory and air humidity $(\mathrm{p})$.

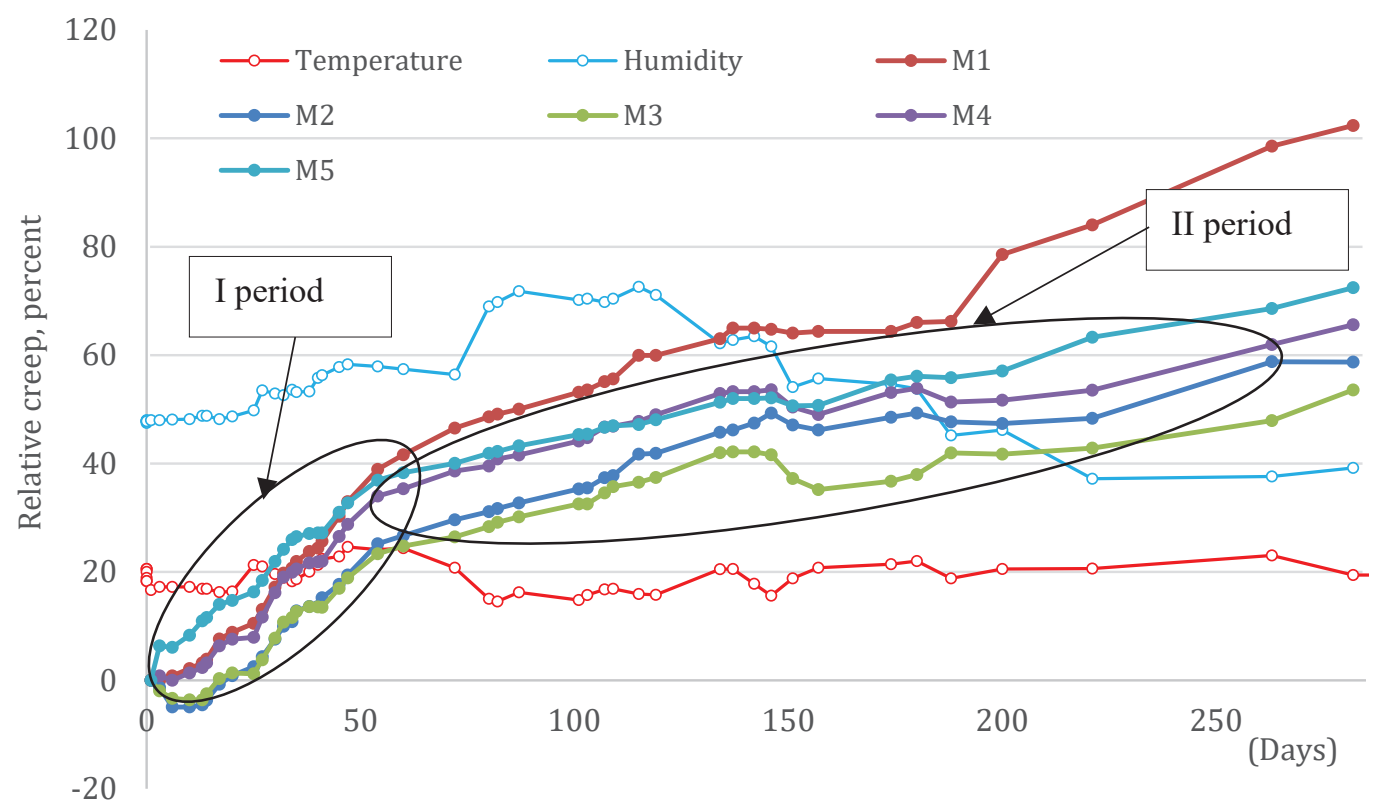

Figure 4. Relative creep for the models with corresponding humidity and temperature data at 280 days loading test. 


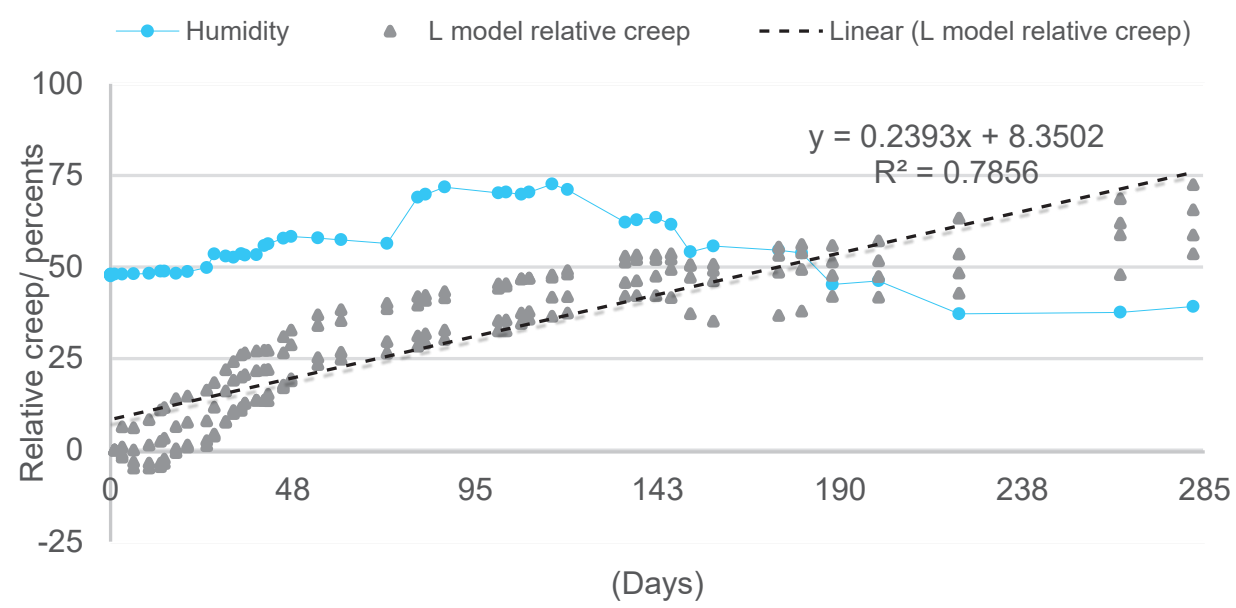

Figure 5. Approximation of average relative creep values in the time data at 280 days loading test.

Graphs for the development of relative creep during the time are shown in Figure 4. Almost all models show a similar increase in relative creep in time, except Model No 1. The average relative creep increase after 60 days was $30 \%$ but after 280 days it was $60 \%$. Development of relative creep for L-type moment-resisting connections can be described distinctively in two periods of time. In the first period, creep permanently increases for the first 60 days under constant air temperature and humidity. In the second period more slowly creep increase is observed and also the influence of air humidity changes is more affecting (Figure 5).

Choosing the best regression model for this type of model is difficult because of on non-linear relationship between relative creep and time. However, during the investigation, different regression models were examined to describe an increase of creep in time (Figure 5).

The theoretical model is shown in Figure 6. The apex point was fixed, and external vertical force $1160 \mathrm{~N}$ (the same as for experimental models) was attached at the lower point. Theoretical results showed that vertical movement of the L-type model is expected of $\mathrm{w}=29.2 \mathrm{~mm}$ and vertical displacement of the lower point was $\mathrm{w}=22.2 \mathrm{~mm}$. Note, that the friction between timber elements was not taken into account by theoretical model and also all fastener at connections were without nuts and plates.

According to measured displacements during long-term tests, the rotational stiffness values $\mathrm{K}_{\varphi}$ were

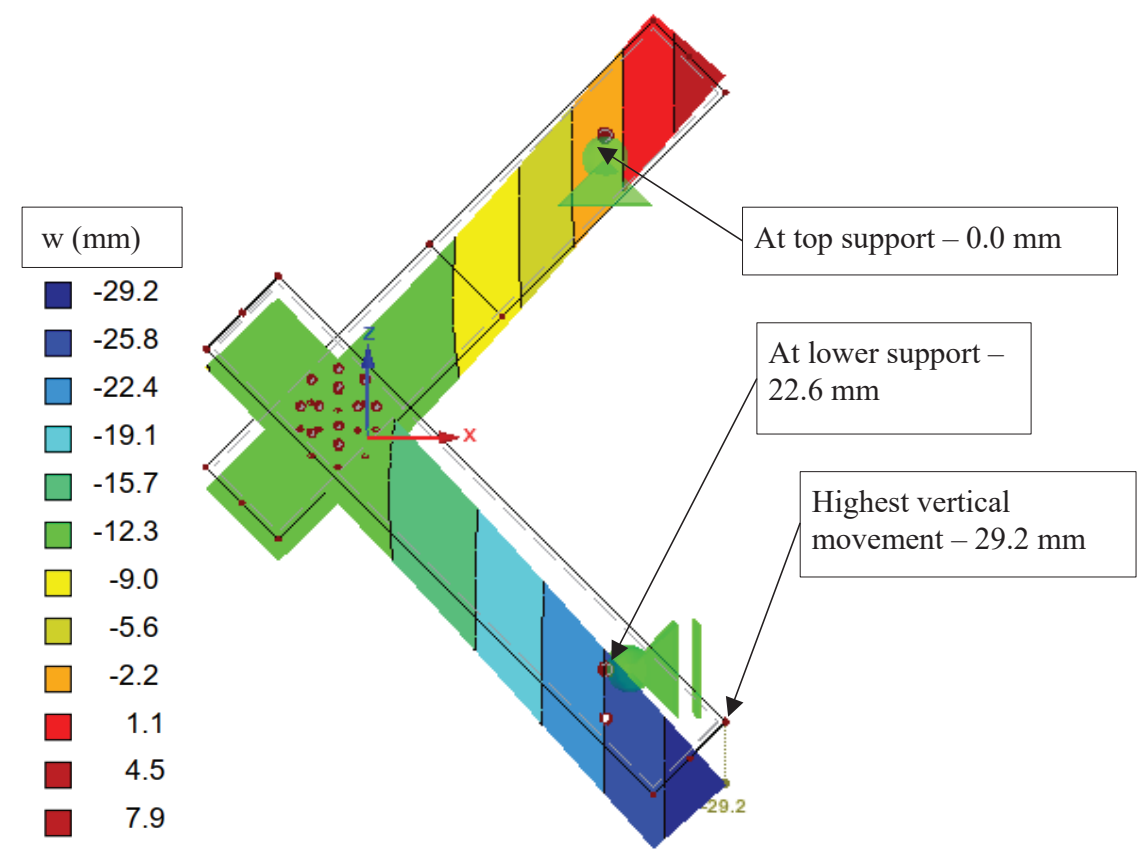

Figure 6. Theoretical model vertical deformations w according to test load. 


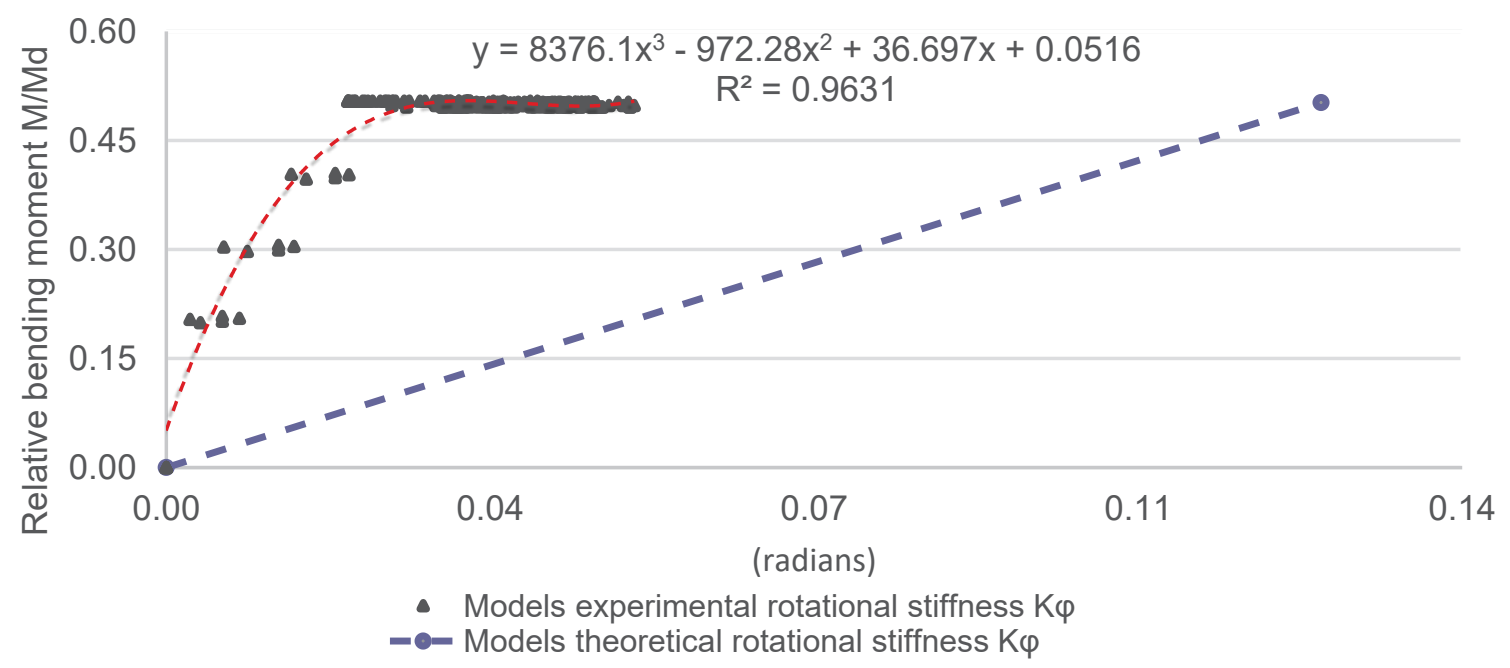

Figure 7. Models theoretical and experimental rotational stiffness at long term loading.

determined. The previous study (Ozola \& Fabriciuss, 2019) proved that semi-rigid connection deformations became non-linear after moment reached 50-60\% from semi-rigid connection bearing capacity. In this investigation, experimental L-type models were loaded average on $52 \%$ from design bearing capacity and non-linear behavior has to be proved by results. The graph (Figure 7) shows that deformations at the start were linear. During long-term loading, the creep deformations are decreasing connection rigidity, permanently increasing the rotational movement. The average rotational stiffness at first day was $\mathrm{K}_{\varphi}=20$ $\mathrm{kN} \cdot \mathrm{m} \cdot \mathrm{rad}^{-1}$ but after 280 days loading period this value decreased twice: $\mathrm{K}_{\varphi}=10 \mathrm{kN} \cdot \mathrm{m} \cdot \mathrm{rad}^{-1}$. Theoretical investigation results show $\mathrm{K}_{\varphi}=4 \mathrm{kN} \cdot \mathrm{m} \cdot \mathrm{rad}^{-1}$ which is two times lower than experiment results.

\section{Conclusions}

Experimental test results show that $60 \%$ of moment resisting model deformations developed on the first day. For the rest of the testing time, the slower increase of deformations was detected.

It is found to be important existing difference in the composition of an experimental and theoretical model when only bolts as structural members were incorporated without plate and nuts, which are at both sides of the test specimens.

Friction between timber elements was not taken into account in the theoretical investigation, but clearly, it increases the models' stiffness.

The development of deformations in time conforms to a non-linear function. Results show that two distinctive periods are characteristic in creep development. In the first period till 60 days, an increase of deformations becomes more intensive, but during the rest of the test time the creep development is lower and more sensitive to environmental conditions.

Numerical analysis showed that vertical movement at a lower point of L-type model was approximately two times bigger than the average experimental test results after 280 days of loading.

Also, experimental test results of L-type models showed that average rotational stiffness is $\mathrm{K}_{\varphi}=20$ $\mathrm{kN} \cdot \mathrm{m} \cdot \mathrm{rad}^{-1}$, but after 280 days of loading period rigidity decreased by two times due to creep effects $\left(\mathrm{K}=10 \mathrm{kN} \cdot \mathrm{m} \cdot \mathrm{rad}^{-1}\right)$. Theoretical investigation shows $\mathrm{K}_{\varphi}=4 \mathrm{kN} \cdot \mathrm{m} \cdot \mathrm{rad}^{-1}$

It is important to investigate the development of deformations in time simulating the knee joint of the timber portal frame to gain the best knowledge about the behavior of dowelled moment connections. Investigation showed that theoretical and practical test results are different. To gain a more adequate numerical model, the friction needs to be determined by experimental tests and corresponding ties integrated into the numerical model.

\section{Acknowledgements}

Publication and dissemination of research results have been financially supported by the Project of Latvia University of Life Sciences and Technologies: Project Z37 'Methodology for determination of rotational stiffness modulus of moment resisting timber connections'.

\section{References}

Awaludin, A., Sasaki, Y., Oikawa, A., Hirai, T., \& Hayashikawa, T. (2010). Moment resisting timber joints with high-strength steel dowels: natural fiber reinforcements. In Proceedings of the $11^{\text {th }}$ World Conference on Timber Engineering 2010, WCTE 2010, Vol. 4, 3213-3220. ISBN: 978-162276175-3. 
European committee for standardization (2008). Eurocode 5: Design of timber structures - Part 1-1: General Common rules and rules for buildings. Proceedings of the ICE - Civil Engineering. DOI: 10.1680/ cien.2001.144.6.39.

Fokkens, T.J.H. (2017). Behaviour timber moment connections with dowel-type fasteners reinforced with selftapping screws in seismic areas. THESIS. Eindhoven University of Technology.

Hanhijärvi, A. (2000). Computational method for predicting the long-term performance of timber beams in variable climates, Materials and Structures, No 226, Vol. 33, March 2000, pp. 127-134.

Leichti, R.J., Hyde, R.A., French, M.L., \& Camillos, S.G. (2000). The continuum of connection rigidity in timber structures. Wood and Fiber Science, Vol. 32, Issue 1, January 2000, 11-19. ISSN: 07356161.

Ormarsson, S., Dahlblom, O., \& Nygaard, M.J. (2010). Finite element simulation of mechanical and moisturerelated stresses in laterally loaded multi-dowel timber connections. In Proceedings of the $11^{\text {th }}$ World Conference on Timber Engineering 2010, WCTE 2010, Vol. 4, 3213-3220. ISBN: 978-162276175-3.

Ozola, L., \& Fabriciuss, J. (2019). Assessment of Semi-Rigidity of Dowel Type Knee Joint between Timber Elements, IOP Conference Series: Materials Science and Engineering - Vol. $471,4^{\text {th }}$ World Multidisciplinary Civil Engineering, Architecture, Urban Planning Symposium (WMCAUS 2018), 052073 - ISSN 1757899X.

Porteous, J., \& Kermani, A. (2013). Structural timber design to Eurocode 5. Chichester, West Sussex, UK: John Wiley \& Sons Inc.

Schweigler, M., Bader, T.K., \& Hochreiner, G. (2018). Engineering modeling of semi-rigid joints with doweltype fasteners for nonlinear analysis of timber structures. Engineering Structures, 171, 123-139. DOI: 10.1016/J.ENGSTRUCT.2018.05.063.

Timber Engineering (1995). Step 1. Edited by H.J. Blaß, P. Aune, B.S. Choo, R. Görlacher, D.R. Griffiths, B.O. Hilson, P. Racher, G. Steck. Netherlands: Centrum Hout.

Hunt, D.G. (1999). A unified Approach to Creep of Wood. Proceedings of The Royal Society, No. 455, pp. 4077-4095. 